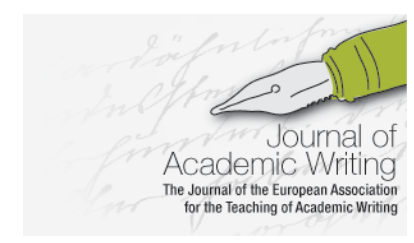

Journal of Academic Writing Vol. 8 No 2 Winter 2018, pages $124-136$ http://dx.doi.org/10.18552/joaw.v8i2.464

\title{
Talking Academic Writing: A Conversation Analysis of One-to-One Learning Development Tutorials
}

\author{
Elizabeth Caldwell \\ University of Huddersfield, UK \\ Katharine Stapleford \\ Leeds Beckett University, UK \\ Amanda Tinker \\ University of Huddersfield, UK
}

\begin{abstract}
Within the Learning Development community there are few professional development opportunities or resources for new entrants to the profession, particularly with regard to conducting individual academic writing tutorials. The current study seeks to address this by analysing the talk of individual academic writing tutorials in order to better understand how tutorials are organised and conducted, how identities and relationships are established and how learning is developed. We analysed the audio recordings of one-to-one academic writing tutorials and used conversation analysis methodology to identify features of effective practice. The analysis revealed an overarching three-part sequential structure to the tutorials and identified several features of effective practice in the middle phase where advice-giving occurs. The key finding was that indirect and complex processes of highlighting problems and arriving at solutions are useful to develop learners' skills and autonomy. The application of these insights has the potential to contribute to a more evidence-informed reflective community of Learning Development practitioners.
\end{abstract}

\section{Introduction}

In UK Higher Education Institutions (HEIs), there exist specialist professionals whose role it is to work with students to 'make sense of the practices and language(s) of higher education' (Hilsdon 2011: 15). This role has become more widespread in response to the Widening Participation agenda and the increase of 'non-traditional' Higher Education students (Hilsdon 2011). In an era of rising student numbers, financial pressures and the conceptualisation of students as consumers, there is an increasing drive to capture and evaluate the work of such professionals. Terms for the role vary between institutions and these professionals are referred to as Academic Skills Tutors, Learning Developers, Study Skills Advisors, and variations thereof; however, for the purposes of this article, the term Learning Developer (LD) will be used. The role of the LD in a UK HEI is performed by members of teaching staff, or 'faculty', who are expected to be qualified at postgraduate level and hold, or be working towards, a teaching qualification. A large proportion of LD work is student-facing and consists of providing generic workshops on a range of academic skills topics, bespoke sessions embedded into course programmes, and small group or one-to-one tutorials. Students book one-to-one tutorials to discuss developing a range of skills required for university study, such as time management, public speaking or academic writing. However, by far the most common reason for booking a tutorial is to seek advice on writing assignments and it is in this context that the current study is situated. 
LDs enter the profession from a range of backgrounds with a wide experience base and, whilst many have had formal training in group teaching, training for one-to-one teaching is less common. Furthermore, there is a dearth of academic literature and practical training guides for one-to-one writing tutorial situations (Webster 2017). The aim of this study was to use conversation analysis (CA) to identify characteristics of effective advice-giving interactions between students and LDs in one-to-one tutorials, in order to then develop training materials for use by established practitioners to reflect on their own practice and in the training of new LDs. The following sections will discuss the research and theoretical underpinning of CA in the context of institutional interaction, an account of CA methodology, the data collection methods and a discussion of the findings in relation to the literature reviewed.

\section{Literature Review}

Capturing, evaluating and enhancing the work of LDs has been a pressing issue for practitioners since the profession's inception. A similar concern is seen in writing centres in the US and, over three decades ago, North argued:

Talk is everything. If the writing center is ever to prove its worth in other than quantitative terms - number of students seen, for example, or hours of tutorials provided - it will have to do so by describing its talk: what characterizes it, what effect it has, how it can be enhanced (1984: 444).

Other professions, such as counselling, routinely record practitioner-client talk for training purposes. These recorded dialogues are analysed using CA to identity formulations (Antaki, Barnes and Leudar 2005, Stokoe and Sikveland 2016), phases of interactions, prompting and active listening (Kitzinger and Kitzinger 2007), empowering interaction strategies (Poskiparta et al. 2001), and identifying barriers (Stokoe 2013). Once identified, strategies to enhance these features can then be incorporated into training sessions for practitioners, which often involve practical exercises such as role play and reflection (see Kitzinger and Kitzinger 2007).

CA examines naturally occurring talk in situ and pays attention to the social actions created through the use of specific language features in particular social situations (Drew and Heritage 1992). As such, attention is given to the underlying social organisation of the context, which is dynamic, created, renewed and oriented to by its participants as they interact. In contrast to everyday talk, in institutional contexts participants are typically oriented towards a particular goal or role identity, which manifests in the sequence of interaction, governing what can and cannot be said (Drew and Heritage 1992, Levinson 1992). As such, by its very nature, CA is comparative. Thonus' (2002) study uses CA to examine academic writing tutorials and notes that these tutorials share features with other institutional interactions such as medical consultations and psychotherapy sessions. Furthermore, writing tutorials also have parallels with discourse in other academic encounters such as teacher-student writing conferences, academic counselling sessions and advising interviews.

Previous research on one-to-one encounters in academic contexts has included research supervision (Svinhufvud and Vehviläinen 2013), teacher training (Kim and Silver 2016, Long, van Es and Black 2013), English as a second language (ESL) tutorials (Belhiah 2009, Belhiah 2011), academic advising (Guthrie 1997), writing conferences (Ulichny and Watson-Gegeo 1989, Walker and Elias 1987) and academic writing centres (Mackiewicz 2005, Thonus 1999, Thonus 2002, Thonus 2008). These studies demonstrated a number of characteristics of oneto-one tutorials, including the fact that, despite the institutional setting, 'turn-taking and sequential structures [...] are more like those found in ordinary conversation' (Guthrie 1997: 397). Moreover, Thonus suggests that the language of writing tutorials is 'far less routinized, scripted, or predictable than the institutional discourse or the classroom, courtroom, and news interviews' (1999: 226). Despite this, Thonus (2002: 166) identifies four phases of writing tutorials: 1) the opening, 2) the diagnosis, 3) the directive, and 4) the closing, with the directive phase taking up the majority of the tutorial. 
In research supervision meetings there is often an expectation of progress occurring in successive tutorials and a heavy orientation to documents (Svinhufvud and Vehviläinen 2013). However, writing centre tutorials are supposed to be based on a 'peer consultation model' and challenge the notion of tutor dominance (Thonus 2016). However, analyses of writing centre consultations show that this is rarely the case in practice, although tutors do often try and build rapport and encourage a degree of informality (Thonus 2002). For example, Thonus (2002) found that features such as simultaneous laughter and small talk solidarity are perceived by participants as characteristics of a successful tutorial. The current study aims to build on the work of Thonus and identify features that characterise productive advice giving during learning development tutorials.

\section{Giving advice}

Park (2017: 253) asserts that advice giving 'is one of the central practices in pedagogical interaction' and that this advice is often constituted as 'giving feedback and proposing a solution to the student'. A number of studies have examined how advice is given in other institutional interactions. Poskiparta et al. (2001) found that the way nurses give advice can either facilitate or hinder patients' reflection (Poskiparta et al. 2001: 70). Similarly, research on advice giving on telephone helplines has found that the call takers try to preserve the caller's autonomy and so present their advice in mitigated forms 'built off the caller's own words', which has the effect of the call takers avoiding full responsibility for the advice given (Shaw and Kitzinger 2007: 210). Mediators are specifically mandated not to give advice to their mediation clients (Stokoe and Sikveland 2016). Instead they are trained to ask solution focused questions (SFQs) to encourage clients to develop their own solutions. However, Stokoe and Sikveland found that mediators do sometimes provide answers to their own SFQs, 'as a way of working towards a solution without providing advice directly' (2016: 105).

Whilst not as strongly mandated as mediators to not offer solutions, both LDs and writing tutors must balance the 'pedagogical dilemma' between giving students constructive feedback on their work and actually doing the students' work for them (Mackiewicz 2005: 373). Previous studies have shown that in academic tutorials, tutors and instructors take control of both the topic and the interaction, particularly in the advice-giving stage of the session (Guthrie 1997, Thonus 1999). During the advice-giving phase, the advisor produces the lengthier turns whilst the student predominantly acknowledges using continuers ('mmhmm') and tokens ('okay') (Guthrie 1997). However, Thonus points out that in writing tutorials, tutors are instructed to 'coach and not fix [...] keep silent [...] let the students do most of the work' (1999: 227) and parallels have been drawn between writing tutorials and psychotherapy sessions where advice is frequently withheld and 'authoritative answers tend to be refused' (Ten Have 1989: 128 cited in Thonus 1999: 226). However, other research has found that students prefer tutors who offer specific suggestions on their work (see Mackiewicz 2005 for a review).

In order to achieve this balance between being overly directive whilst still giving constructive feedback, Thonus (1999: 240) found that graduate writing tutors use a range of mitigation strategies, for example: 'I was wondering, maybe, maybe you need to qualify that a little bit'. Although the use of mitigation strategies ensures that the tutor is polite, it also means that the inferential path, or the distance between what people mean and what they say, is longer and there is greater potential for misunderstanding (Mackiewicz and Riley 2003). Mackiewicz (2005) noted that writing tutors regularly sacrifice clarity in favour of politeness, so as not to affect the student's confidence. Kim and Silver (2016) found that teacher trainers regularly use questions with trainee teachers to elicit reflections and evaluations of the trainees' teaching. However, they also observed that if questions were not specific enough, the trainee was unable to answer and it 'made the interaction rather like a mind-reading game' (Kim and Silver 2016: 214). As such, it seems that there is a delicate balancing act between clarity and being overly directive when giving feedback in tutorial situations.

The literature reviewed here clearly indicates the usefulness of CA for identifying features of effective talk in one to one situations. Furthermore, CA of real interactions with caregivers and service users has been used to develop training materials and techniques for professionals in a variety of contexts (Kitzinger and Kitzinger 2007, Stokoe 2013). However, to date, there has been little such research conducted in the context of the professional LD academic writing 
tutorial and there are very few materials on techniques and strategies for effective one-to-one teaching. Consequently, this study aims to address this by applying CA in the learning development context, in order to answer two research questions:

1. What is the overarching structure and verbal shape of key features of one-to-one learning development tutorial interaction?

2. What are the features of effective practice of one-to-one academic writing tutorial interaction in relation to offering feedback and giving advice?

\section{Methodology}

The context for this study is a small mixed economy group (Higher Education in Further Education) campus in the north of England offering a range of undergraduate degrees in vocational disciplines. The institution was established in response to the Widening Participation agenda and has a large proportion of non-traditional Higher Education students, who are unfamiliar with the scholarly practices of higher education. The data for this study consists of 17 audio recordings of one-to-one academic skills tutorials, lasting between 30 and 60 minutes each, totaling 11 hours of audio data. The participants represented a range of subject disciplines and were at different points in their studies; the majority were undergraduate with some postgraduate professional training students. Ethical approval was given by the institution in question and informed consent was obtained for all participants and recordings were anonymised.

CA of recorded speech is inductive and detailed, working with audio and meticulous transcripts of the interaction (See Appendix for transcription code). As such, the recordings were professionally transcribed and the research team worked closely with the audio recordings and transcriptions in 'data sessions' which proceeded as described here:

One common way is for one person to bring in a piece of data - such as a telephone call or video recording - and associated transcript. The data is then viewed repeatedly, at least two or three times depending on length. A decision is then made about where in the data segment to focus observations. This can be a turn, a small sequence or any other noticeable feature of the talk. Once a decision is made the participants take time to make their own observations. Once everyone has had time to make notes, observations are shared among members of the group. (Sidnell 2010: 29)

This process was repeated on several occasions and resulted in a number of notable features and patterns both within a single transcript and across multiple transcripts.

Identifying the overarching, macro-sequence of the interaction context is often the first part of the analysis process before the detail is examined. First, the overarching structure of tutorials from all 17 recordings was analysed, and recognisable phases of the interaction were identified. Following this, we focussed on a number of socially relevant actions that occurred across the data set and were relevant to LD practice, including non-preferred answers to student requests, signaling errors and advice giving. We were interested in how these are manifest in the turn design of participants' speech (the verbal shape and lexical choice). For this article we focus on the sequencing and verbal shape of advice giving in one-to-one LD tutorials. As is usual practice in CA, in the next section we first present the overall sequence found in tutorials, arising from analysis of all 17 tutorials. Following this we analyse in detail part of one tutorial, as a representative example of a typical advice-giving interaction.

\section{Findings and Discussion}

\section{Overall tutorial sequence}

As discussed earlier, one of the first stages of CA is to determine the overarching nature and structure of the interaction, as grounded in the transcripts. Our data demonstrated that students arrive at the tutorial with an expectation; they are seeking advice, help with a task (usually 
assignment-related), a perceived problem, or simply reassurance. The LD's role is then to respond to this expectation by identifying issues, offering suggestions or solutions whilst at the same time encouraging autonomy. In terms of general structure, the tutorials tended to display a three-part organisation:
1. Openings.
2. Responding to the problem/task.
3. Closings.

As mentioned earlier, Thonus' (2002) analysis of writing tutorials identified four general stages, starting with two short stages: Openings and Diagnosis. In our data set, there was no clear separation between these two stages and the diagnosis was frequently iterative as the tutor probed the student to discover their motivations for booking a tutorial and what their agenda was for the session. This perhaps reflects the wider remit of LD tutorials, compared to writing centre consultations as there are many more possible reasons that the student has come, and although a piece of writing is frequently discussed, it is not uncommon for a number of other skills, assignments or pastoral issues to be discussed in the same tutorial. As such, our three stage organisation is not only based on our data set, but also captures the variety of typical activities that occur in each phase (see Tables 1-3).

Table 1 illustrates typical activities occurring in tutorial openings, with examples of turn design.

Table 1. Tutorial Opening Sequence

\begin{tabular}{|c|c|}
\hline Activity & Example Turn Design \\
\hline $\begin{array}{l}\text { Rapport building } \\
\text { Opening } 1 \text { (general) }\end{array}$ & LD: So what are we looking at today then? \\
\hline $\begin{array}{l}\text { Problem presentation (often with } \\
\text { an account) }\end{array}$ & $\begin{array}{l}\text { S: I've done part of it but I'm not quite sure I'm going in } \\
\text { the right direction } \\
\text { S: I didn't finish my assignment 'cos I need a little bit of } \\
\text { help from you. }\end{array}$ \\
\hline $\begin{array}{l}\text { Establishing prior knowledge } \\
\text { Reference to previous tutorials } \\
\text { Practicalities/locating documents } \\
\text { Checking brief/identifying task } \\
\text { Student reports progress so far }\end{array}$ & $\begin{array}{l}\text { LD: So before you came here what academic writing did } \\
\text { you do? } \\
\text { LD: So you're producing an action plan }[\ldots] \text { and a } \\
\text { commentary. }\end{array}$ \\
\hline Opening 2 (focus) & $\begin{array}{l}\text { LD: So what would you like to focus on today? } \\
\text { LD: So is there something specific you're unsure of? }\end{array}$ \\
\hline Problem reformulation & $\begin{array}{l}\text { S: She was saying we have to include theoretical aspects } \\
\text { so it was a bit tricky for me. } \\
\text { S: I'm struggling to linking up to um I'm struggling to link } \\
\text { to link up some words. It just becomes repetitive. }\end{array}$ \\
\hline
\end{tabular}

The tutorial interaction typically begins with a period of general conversation, typically led by the LD, which could be viewed as a form of rapport-building. Orienting to their institutional role, the LD then initiates 'the business' by opening with a general question to elicit the current problem or task, often preceded by the discourse marker 'so' (for further discussion see Bolden 2008, Stoke and Sikveland 2016). The student then presents a version of the general problem, often with an account to justify the need for help. The problem can be expressed quite vaguely at this stage therefore it is the role of the LD to gather more information, explore the problem 
and 'drill down'. Although the tutorial is a two-party interaction, a hidden third party (subject discipline tutor) is often brought into the interaction by either the LD ('You'll need to check this with your module tutor') or the student ('My tutor has said [...]'). This practice was similarly observed in home birth helpline talk, when either participant might defer to an absent General Practitioner or midwife for the requisite knowledge or to indicate role remit (Shaw and Kitzinger 2007).

The main business of the tutorial then ensues, as the LD responds to the problem/task (see Table 2).

Table 2. Responding to the Problem/Task: Typical Activities

\begin{tabular}{|c|c|}
\hline LD Activities & Student Activities \\
\hline Questioning/eliciting & Continuers (yeah) \\
\hline Formulation/reformulation (So) & $\begin{array}{l}\text { Agreement (minimal responses - } \\
\text { right, ok) }\end{array}$ \\
\hline $\begin{array}{l}\text { Preference (boundaries/roles) (Pomerantz 1984, } \\
\text { Schegloff 2007, Stokoe 2013) }\end{array}$ & Formulation \\
\hline Display (expertise) (Parry 2004, MacKiewicz, 2005) & Reformulation of problem \\
\hline Evaluation (indirect, questions, tag questions) & $\begin{array}{l}\text { Disagreement/challenge (less } \\
\text { common) }\end{array}$ \\
\hline $\begin{array}{l}\text { Suggesting (mitigated, modal verbs) } \\
\text { Reader expectations }\end{array}$ & $\begin{array}{l}\text { Accounts (saving face after } \\
\text { evaluation) }\end{array}$ \\
\hline Modelling (academic conventions) & I ran out of time \\
\hline Praise & $\begin{array}{l}\text { Just shoved it in today cos } \\
\text { it came to my mind }\end{array}$ \\
\hline Directive/instructional (You need to) & Just a draft \\
\hline $\begin{array}{l}\text { Reassurance (Well I think you seem to be on the right } \\
\text { lines) and to start to signal closure }\end{array}$ & \\
\hline
\end{tabular}

Exploration of the problem by the LD continues with questioning and formulation/reformulation and role boundaries continue to be negotiated through preference and display activities, where, for example, the student may seek proofreading, grade feedback or subject advice, yet is given a 'dispreferred response' (see Pomerantz 1984, Schegloff 2007, Stokoe 2013). Evaluation and suggestions by the LD (explored in more detail in the following section) are typically indirect and mitigated, and modelling and reader expectation are used to convey academic convention, demonstrate feasibility and ultimately encourage student acceptance. The tutorial is therefore guided by the LD and the student adheres by providing continuers, agreements and minimal responses. Challenge is rare, yet accounts are often provided after LD evaluation to defend, save face, or explain. 
Table 3. Tutorial Closing Sequence

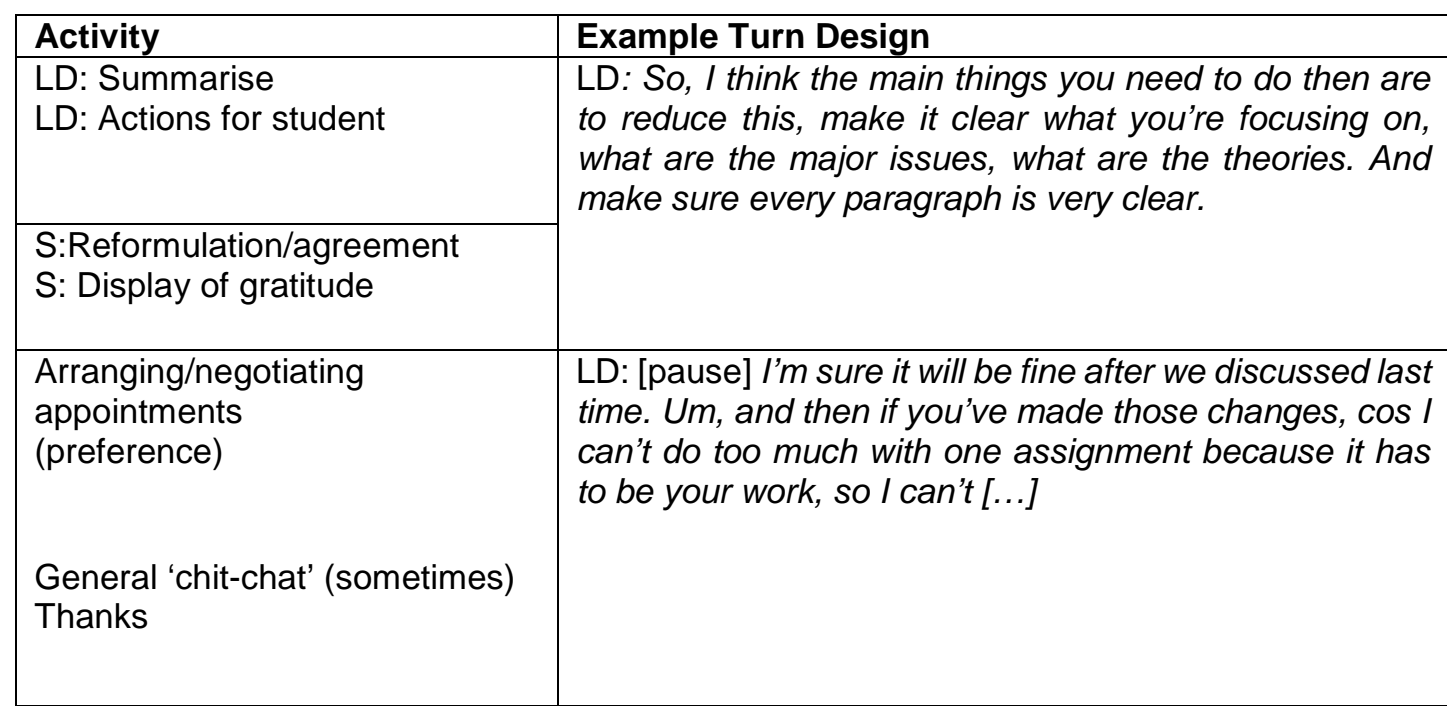

Closings are typically LD-initiated with reassurance (Table 2), summaries or action formulations, which the student may reformulate as a sign of agreement (Table 3). The sometimes tricky issue of the next tutorial is negotiated; again, preference activities may be observed; and the tutorial closes with pleasantries and gratitude.

\section{Giving advice in tutorials}

The following discussion will examine in detail an extract of one of the tutorials in our data set in order to explore how suggestions and advice are negotiated between LD and student. This extract was chosen as it demonstrates in a single sequence all the features of advice giving that were identified across the data set. The LD in the extract was an experienced ESL teacher and teacher trainer and the student was a near native speaker and a final year undergraduate student, studying a vocational course. The student had seen the LD a number of times previously and this particular session lasted 30 minutes and centred around discussing a piece of writing that the student was working on. At the start of the session the LD and student negotiate the focus of the session. The tutorial then proceeds with the LD reading through the student's writing and, at various points, stopping to highlight issues in the text and discuss possible solutions to them. The LD signals that there is something they want to discuss by using the phrase: 'I'm not sure about', which contains an inherent, albeit mild, evaluation (see Mackiewicz 2005). However, this phrase also implies that there is a problem with the reader, and not necessarily with the text or the student and in this way the LD ensures that the student's 'face' is not overly threatened (see Figure 1)

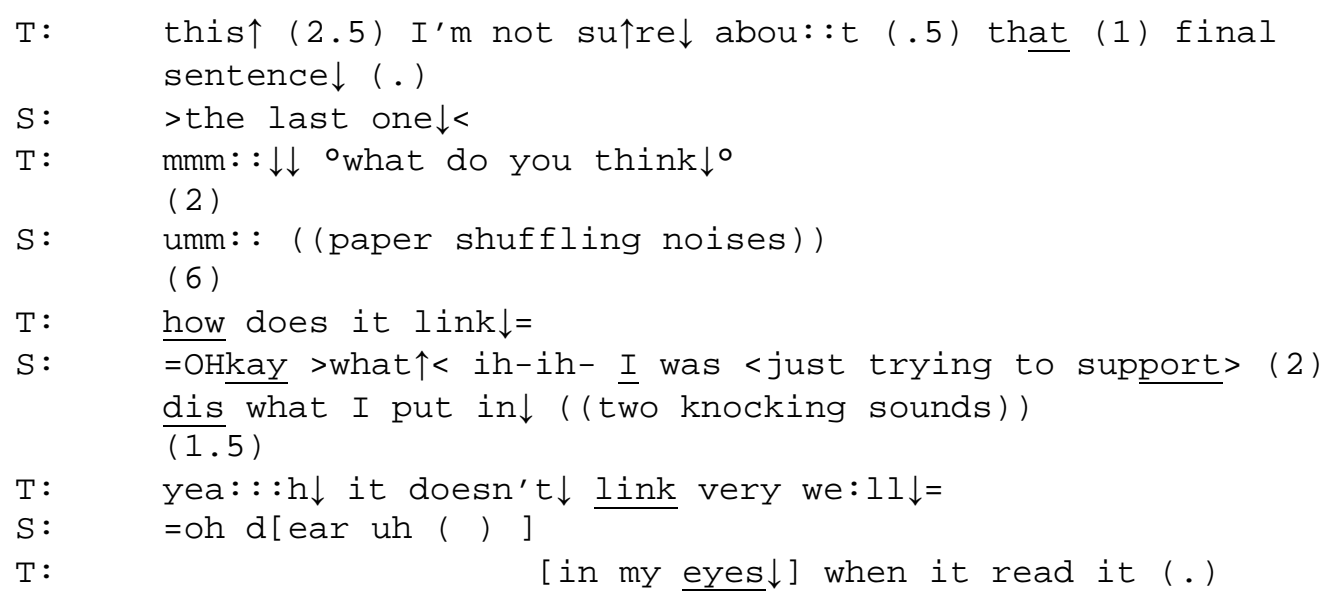

Figure 1. Signaling an Issue 
Previous research on writing tutorial interactions has found that tutors repeatedly cycle through tight evaluation-suggestion sequences (Thonus 1999). However, as is common practice with the LD observed in this study, they hand over to the student and try to elicit the nature of the problem from them by saying 'What do you think?' This gives an opportunity for the student to respond and spot the problem, and also implicitly tries to gain agreement from the student that there is actually a problem with the text. Eliciting the problem from the student, rather than telling them what is wrong, is good practice in both ESL teaching and teacher training, and it is possible that this LD's background in these roles has influenced their style of giving feedback. As discussed earlier, Kim and Silver (2016) found that the danger with eliciting problems from students is that they may not recognise that there is a problem, or be able to articulate what the problem is. Similarly, in the current tutorial, the student is at a loss as to how to reply and the LD has to ask a prompting question: 'How does it link?' This is an example of a reversed polarity wh-question, which can be used to convey a negative assertion, in this case: 'It doesn't link' (see Koshik 2005). When the student still does not recognise the issue, the tutor then has to reformulate this as a stronger evaluation: 'Yeah, it doesn't link very well, in my eyes'. However, by using the personal pronoun 'my' the LD is still implying that there is a subjective element to the evaluation, which is perhaps less face-threatening than pointing out a categorical error.

In response to the LD articulating the problem with the text, the student very quickly suggests a solution, which is to delete the sentence (see Fig 2). However, the LD seems uncomfortable with this rapid suggestion and hints at an alternative option: to explain the relevance of the sentence. The student still seems unsure as to how to make the sentence link better as they continue to give an account to justify their original composition. As a result, the LD reformulates the advice several times in progressively more direct ways: 'but you need to make it clearer' (Fig 2).

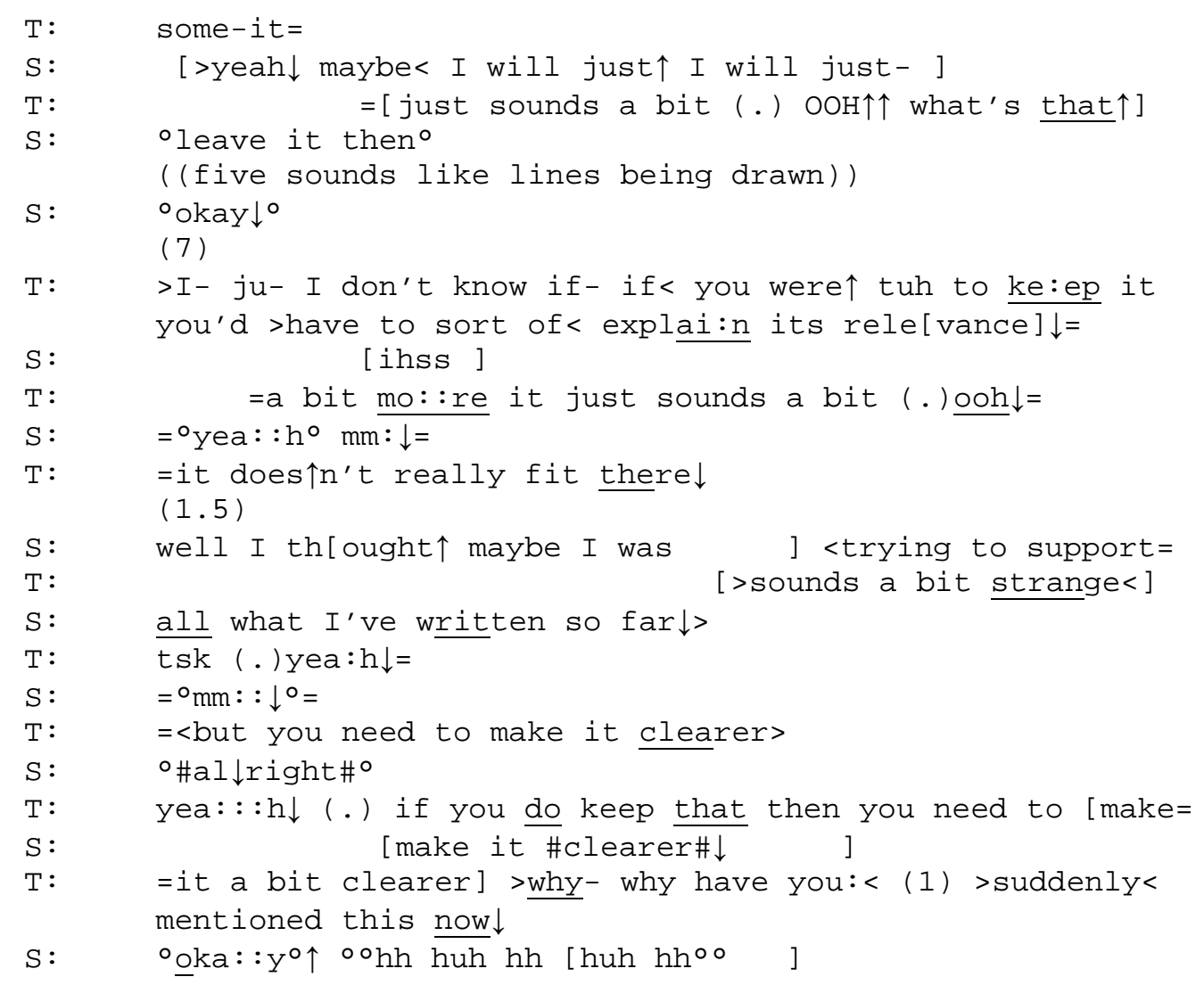

Figure 2. Negotiating a Solution

Finally, the LD tentatively suggests a practical solution: 'So maybe you, it might be better if you put it at the beginning' (Fig 3). This is a conventionally indirect suggestion, using a mitigator (maybe) and conditional (might) so that the LD appears to not be telling the student directly 
what to do, but instead makes a hypothetical suggestion. Furthermore, the LD changes the pronoun 'you' to 'it' to give the impression that the LD has no personal claim in the solution and so that the student can eventually 'own' it. In this case, the student embraces the solution and repeats it with gusto, and, so, finally resolution is reached about what will be done with this problematic sentence. Interestingly, after using this extract in a conference workshop with a large group of experienced LDs a number of the workshop participants commented that they felt the student had come up with this solution, even though it was in fact the tutor who first suggested it (Stapleford, Caldwell and Tinker 2017). This echoes the findings of Stokoe and Sikveland (2013) where it is in fact the mediators who suggest answers to their own SFQs, albeit in subtle ways so that clients can 'buy in' to solutions.

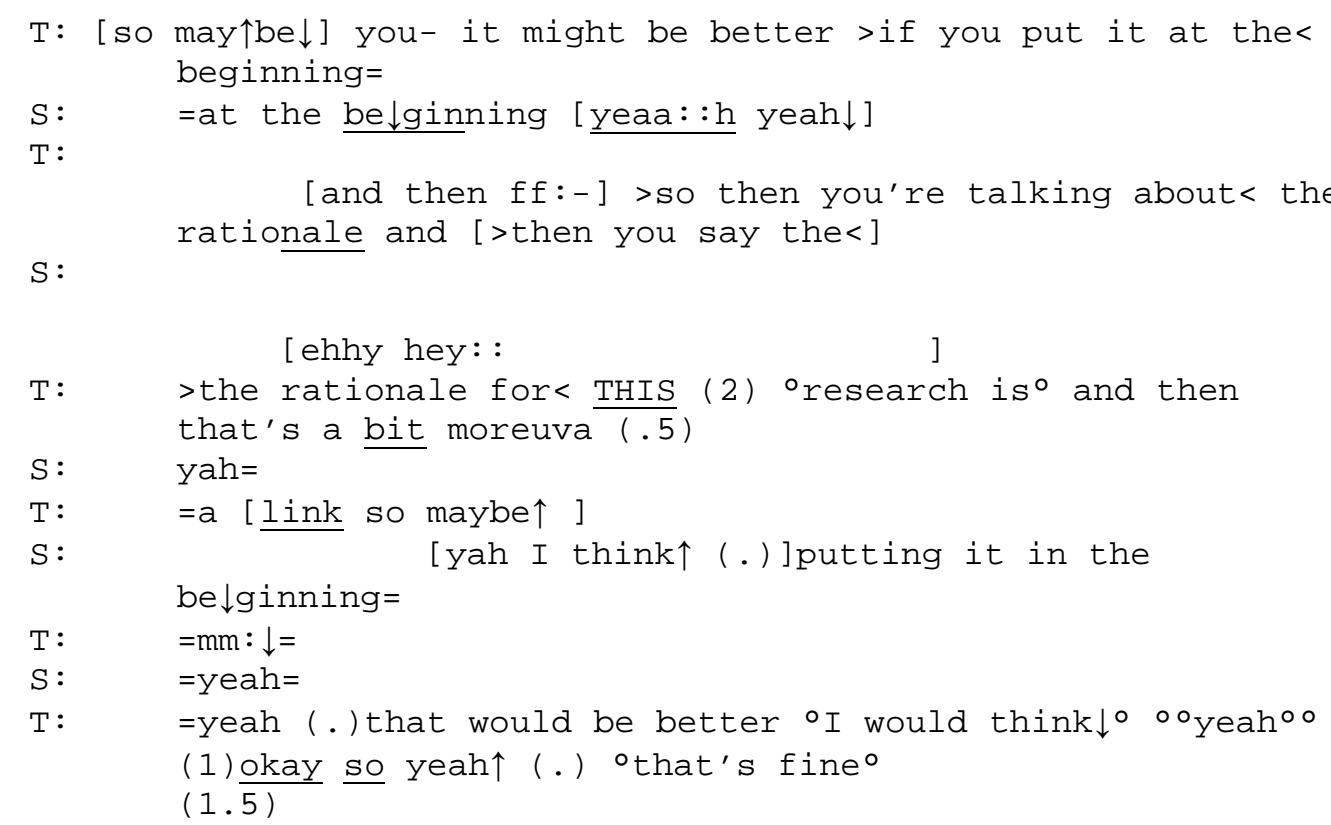

Figure 3. Agreeing a Solution

This exchange takes a total of 1 minute and 38 seconds, during which the LD greatly lengthens the inferential path by using questions, followed by evaluations to get the student to come up with the solution, rather than telling them directly what the problem is and how they should fix it. Interestingly, unlike in previous studies of writing tutors (Mackiewicz 2005, Thonus 1999), the LD does not seem to be doing this for reasons of politeness as they are not afraid to be direct when the student is unable to see the problem. It seems that the LD is going through this lengthy and time-consuming process over a single sentence in order to help the student develop their skills at appraising their own writing and editing skills. Much of the previous literature on giving suggestions in tutorials concludes that tutors should be more direct in order to lessen the chance of student confusion (Kim and Silver 2016, Mackiewicz 2005). However, our example demonstrates that when done skilfully, progression from general questions to more specific, combined with using hints that may become progressively more direct, means that student learning can be scaffolded so that students are able to recognise and then fix problems in their writing themselves. Furthermore, by highlighting the effect on the reader and emphasising the process of evaluating writing with the student, the LD is modelling behaviour that could eventually become internal for the student as they appraise and edit their own writing.

\section{Conclusion}

This study has used a CA approach to define the overall organisation of the academic writing tutorial as being conducted in three phases: 1 ) openings; 2) responding to the problem/task; 3 ) closings. Furthermore, this article has focussed on advice giving, which frequently occurs in phase 2. Key features of giving advice include the use of indirect phrases to signify a problem and lengthening the 'inferential path' as a means to scaffold the student's development to help 
them to recognise problems and generate solutions. As is common in CA research (see Kitzinger and Kitzinger 2007), this study analysed the talk of one practitioner with a range of clients. However, further studies drawing on a wider range of LDs and contexts would be useful to broaden the findings with regard to our initial aim of establishing the repertoire of talk used in academic writing tutorials.

These insights have significant implications for the understanding of how effective individual writing tutorials proceed and can help inform professional development of LD practitioners in both formal and informal self-reflection. As indicated earlier, we have already used extracts from our transcripts in workshops on delivering one-to-one tutorials with LD professionals. Participants were asked to reflect on the extracts and identify features of good practice. It is clear that there is significant further potential for our analysis to be incorporated into training materials for example, a useful development activity might be 'stimulated recall' in which practitioners reflect on recordings of a tutorial verbalising the thought processes behind their utterances with a view to consolidating effective and improving less effective practice. Future work resulting from this study will be to develop materials, including role play activities and reflective exercises (see Kitzinger and Kitzinger 2007, Stokoe 2013), which will be shared with the LD community and which it is hoped will contribute to a more reflective and evidence informed community of Learning Developers.

\section{Acknowledgements}

The authors would like to thank the Association for Learning Development in Higher Education, who provided funding for the transcription of audio for this project. We also wish to thank Ruth Watkins for transcribing the audio recordings, Liz Marsden for the specialist conversation analysis transcription and Dr Liz Holt for advice and guidance on conducting conversation analysis. 


\section{References}

Antaki, C., Barnes, R., and Leudar, I. (2005) 'Diagnostic Formulations in Psychotherapy'. Discourse Studies 7 (6), 627-647

Belhiah, H. (2009) 'Tutoring as an Embodied Activity: How Speech, Gaze and Body Orientation are Coordinated to Conduct ESL Tutorial Business'. Journal of Pragmatics 41 (4), 829841

Belhiah, H. (2011) 'You Know Arnold Schwarzenegger? On Doing Questioning in Second Language Dyadic Tutorials'. Applied Linguistics 33 (1), 21-41

Bolden, G.B. (2008) "So What's Up?": Using the Discourse Marker "So" to Launch Conversational Business'. Research on Language and Social Interaction 41 (3), 302337

Drew, P., and Heritage, J. (1992) 'Analyzing Talk at Work: An Introduction'. in Talk at Work. ed. by Drew, P., and Heritage, J. Cambridge: Cambridge University Press, 3-65

Guthrie, A. M. (1997) 'On the Systematic Deployment of Okay and Mmhmm in Academic Advising Sessions'. Pragmatics 7 (3), 397-415

Hilsdon, J. (2011) 'What is Learning Development?'. in Learning Development in Higher Education. ed. by Hartley, P., Hilsdon, J., Keenan, C., Sinfield, S., and Verity, M. Basingstoke: Palgrave Macmillan, 13-27

Jefferson, G. (2004) 'Glossary of Transcript Symbols with an Introduction'. in Conversation Analysis: Studies from the First Generation. ed. by Lerner, G. H. Amsterdam: John Benjamins, 13-31

Kim, Y., and Silver, R. E. (2016) 'Provoking Reflective Thinking in Post Observation Conversations'. Journal of Teacher Education 67 (3), 203-219

Kitzinger, C., and Kitzinger, S. (2007) 'Birth Trauma: Talking with Women and the Value of Conversation Analysis'. British Journal of Midwifery 15 (5), 256-264

Koshik, I. (2005) 'Alternative Questions Used in Conversational Repair'. Discourse Studies 7 (2), 193-211

Levinson, S. C. (1992) 'Activity Types and Language'. in Talk at Work. ed. by Drew, P., and Heritage, J. Cambridge: Cambridge University Press, 66-100

Long, J. J., van Es, E. A., and Black, R. W. (2013) 'Supervisor-Student Teacher Interactions: The Role of Conversational Frames in Developing a Vision of Ambitious Teaching'. Linguistics and Education 24 (2), 179-196

Mackiewicz, J., and Riley, K. (2003) 'The Technical Editor as Diplomat: Linguistic Strategies for Balancing Clarity and Politeness'. Technical Communication 50 (1), 83-93

Mackiewicz, J. (2005) 'Hinting at What They Mean: Indirect Suggestions in Writing Tutors' Interactions with Engineering Students'. IEEE Transactions on Professional Communication 48 (4), 365-376

North, S. M. (1984) 'The Idea of a Writing Center'. College English 46, 433-446

Park, I. (2017) 'Questioning as Advice Resistance: Writing Tutorial Interactions with L2 Writers'. Classroom Discourse 8 (3), 253-270 
Pomerantz, A. (1984) 'Agreeing and Disagreeing with Assessments: Some Features of Preferred/ Dispreferred Turn Shapes'. in Structures of Social Action: Studies in Conversational Analysis. ed. by Atkinson, J. M., and Heritage, J. Cambridge: Cambridge University Press, 57-101

Poskiparta, M., Liimatainen, L., Kettunen, T., and Karhila, P. (2001) 'From Nurse-Centered Health Counseling to Empowermental Health Counseling'. Patient Education and Counseling 45 (1), 69-79

Schegloff, E. A. (2007) Sequence Organization in Interaction: A Primer in Conversation Analysis, Volume 1. Cambridge: Cambridge University Press

Shaw, R., and Kitzinger, C. (2007) 'V. Problem Presentation and Advice-Giving on a Home Birth Helpline'. Feminism and Psychology 17 (2), 203-213

Sidnell, J. (2010) Conversation Analysis: An Introduction. Chichester: Wiley-Blackwell

Stapleford, K., Caldwell, E., and Tinker, A. (2017) 'Analysing the One-to-One Tutorial: A Conversation Analysis Approach'. ALDinHE 2017: The Learning Development Conference. held 10-12 April 2017 at University of Hull

Stokoe, E. (2013) 'Overcoming Barriers to Mediation in Intake Calls to Services: Research Based Strategies for Mediators'. Negotiation Journal 29 (3), 289-314

Stokoe, E., and Sikveland, R. (2016) 'Formulating Solutions in Mediation'. Journal of Pragmatics 105, 101-113

Svinhufvud, K., and Vehviläinen, S. (2013) 'Papers, Documents, and the Opening of an Academic Supervision Encounter'. Text and Talk 33 (1), 139-166

Thonus, T. (1999) 'Dominance in Academic Writing Tutorials: Gender, Language Proficiency, and the Offering of Suggestions'. Discourse and Society 10 (2), 225-248

Thonus, T. (2002) 'Tutor and Student Assessments of Academic Writing Tutorials: What is "Success"?' Assessing Writing 8 (2), 110-134

Thonus, T. (2008) 'Acquaintanceship, Familiarity, and Coordinated Laughter in Writing Tutorials'. Linguistics and Education 19 (4), 333-350

Thonus, T. (2016) 'Time to Say Goodbye: Writing Center Consultation Closings'. Linguistics and Education 33, 40-55

Ulichny, P., and Watson-Gegeo, K. A. (1989) 'Interactions and Authority: The Dominant Interpretive Framework in Writing Conferences'. Discourse Processes, 12 (3), 309-328

Walker, C. P., and Elias, D. (1987) 'Writing Conference Talk: Factors Associated with High and Low-Rated Writing Conferences'. Research in the Teaching of English, 21 (3), 266-285

Webster, H. (2017) 'Developing the Developers'. ALDinHE 2017: The Learning Development Conference. held 10-12 April 2017 at University of Hull 


\section{Appendix: CA Transcription Codes (see Jefferson 2004)}

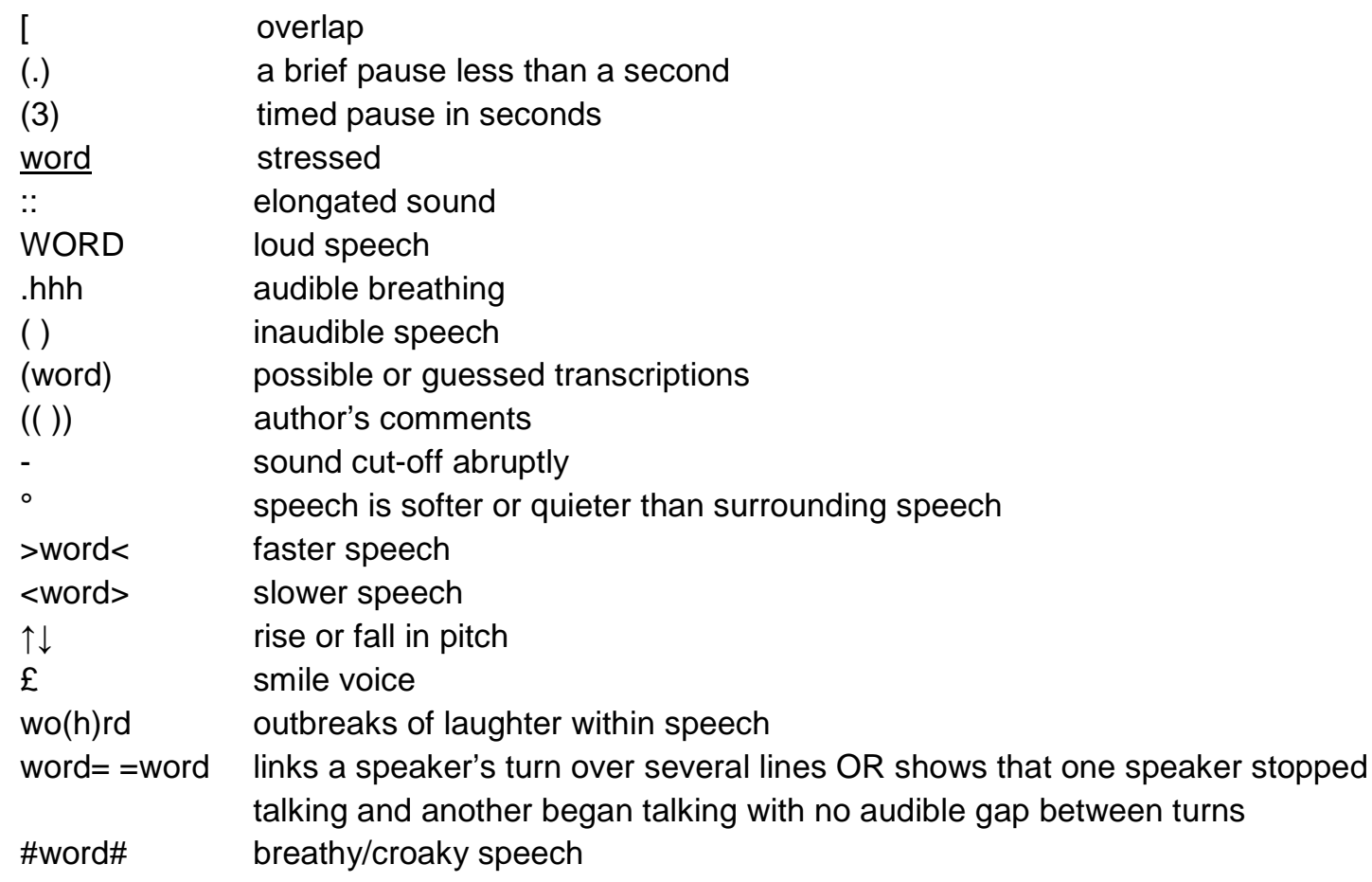

